https://dx.doi.org/10.4314/ijs.v21i3.8

Ife Journal of Science vol. 21, no. 3 (2019)

\title{
CHARACTERIZATION OF ENTEROCOCCUS SPECIES ISOLATED FROM ABATTOIR ENVIRONMENT IN BENIN CITY, NIGERIA
}

\author{
Igbinosa, I. H. ${ }^{1}$ and Raje, O. C. ${ }^{2}$ \\ ${ }^{1}$ Department of Environmental Management and Toxicology, Faculty of Life Sciences, University of Benin, Private Mail \\ Bag 1154 Benin City 300001, Nigeria. 'Applied Microbial Processes \& Environmental Health Research Group, \\ Department of Microbiology, Faculty of Life Sciences, University of Benin, Private Mail Bag 1154 Benin City 300001 , \\ Nigeria. \\ *Corresponding author's E-mail: isoken.igbinosa@uniben.edu \\ (Received: $19^{\text {th }}$ June, 2019; Accepted: $21^{\text {st }}$ September, 2019)
}

\section{ABSTRACT}

Enterococci are primarily inhabitants of the intestinal mucosa of animals and humans; however, they can also be recovered from water, soil, plants, insects and fermented food products. The aim of this study was to carry out quality indices survey for Enterococcus species from the abattoir environment in Benin City, Edo State, Nigeria. A total of 36 samples were obtained from two different abattoirs which comprised of water source $(n=12)$, effluent from point of usage $(n=12)$ and effluent from point of discharge $(n=12)$ between February and July, 2017. Physicochemical variables of the effluents were assessed using standard analytical techniques. The isolation of Enterococcus isolates was carried out using standard culture-based techniques. Analytical profile index 20E (API 20E) was used to confirm the identity of the Enterococcus species. Antimicrobial susceptibility profile of the Enterococcus species was determined using disk diffusion method. The mean ranges of physicochemical parameters of the water samples were: $\mathrm{pH}(5.36 \pm 0.85-7.35 \pm 0.28)$, phosphate $(0.39 \pm 0.31$ $21.28 \pm 0.01 \mathrm{mg} / \mathrm{L})$, dissolved oxygen $(0.83 \pm 1.94-6.13 \pm 0.13 \mathrm{mg} / \mathrm{L})$ and chemical oxygen demand (COD) $(35.66 \pm 0.13-797.10 \pm 0.35 \mathrm{mg} / \mathrm{L})$. The mean range of mesophilic bacteria count was $(6.51 \pm 0.61) \times 10^{7}-$ $(1.92 \pm 0.11) \times 10^{8} \mathrm{cfu} / \mathrm{ml}$ and Enterococcus species- $(6.66 \pm 1.63) \times 10^{1}-(1.16 \pm 0.05) \times 10^{4} \mathrm{cfu} / \mathrm{ml}$. The percentage occurrence of Enterococcus species were: E. faecalis $(29.7 \%)$, E. faecium (35.9\%), E. durans (14.1\%), E. casseliflavus (12.5\%) and E. hirae (7.8\%). A total of $23(35.9 \%)$ of Enterococcus species were resistant to 9 antibiotics $\left(\mathrm{PEN}^{\mathrm{R}}, \mathrm{PTZ}^{\mathrm{R}}, \mathrm{ETP}^{\mathrm{R}}, \mathrm{MEM}^{\mathrm{R}}, \mathrm{TET}^{\mathrm{R}}, \mathrm{CLI}^{\mathrm{R}}, \mathrm{CRO}^{\mathrm{R}}, \mathrm{CTX}^{\mathrm{R}}\right.$, and $\mathrm{VAN}^{\mathrm{R}}$ ) which belong to 6 groups of antimicrobial with a multiple antibiotic resistance (MAR) index of 0.64 . The presence of multiple antibiotic resistant indexes in Enterococcus species is of significance to public health. Findings from this study could be used as a baseline study to investigate outbreaks of pathogenic and multidrug resistant enterococci infections in abattoir environments.

Keywords: Enterococcus, Abattoir, Antimicrobial resistance, Environment, Multidrug resistance

\section{INTRODUCTION}

Enterococcus is an extremely versatile bacterial genus, which is found predominantly in the gastrointestinal tract of humans and animals (Castillo-Rojas et al., 2013). Enterococci are mainly opportunistic pathogen that are harmless in healthy individuals and mainly cause infection in patients who are in intensive care units, with underlying disease or who are immune compromised (Martins et al., 2015). Enterococci are ranked among the most prevalent organisms encountered in nosocomial infections which cause bacteraemia, endocarditis, urinary tract and other infections. Enterococci are the third most common cause of endocarditis in hospitals (Iweriebor et al., 2015).

Enterococcus species is also an indicator of faecal contamination. Two species are common commensal organisms in the intestine of humans which are E. faecalis (90-95\%) and E. faecium (5$10 \%)$. Others with rare clusters of infections include $E$. casseliflaus, E. gallinarum and $E$. raffinosus (Ali et al., 2013). Enterococcus spp. can be found in abattoir environment as well as wastewater treatment plants. Since some abattoirs are unhygienic, presence of pathogens has been detected. These pathogens have been reported to cause diseases such as diarrhea in human and the water contaminated by abattoir waste also contributes to such hazards (Sedlacek et al., 2013). The release of wastewater from slaughter houses into the environment has increased due to the consistent and constant demand for meat so as to meet the needs of the ever increasing population. The meat processing industry produces large 
volumes of slaughterhouse wastewater due to the slaughtering of animals and cleaning of the slaughterhouse facilities and meat processing plants (Sadowy and Luczkiewicz, 2014).

Efforts have been geared towards curbing the menace of pollution around the world particularly by the United Nations organs, for example, United Nations Environmental Programme and there are many international conference and protocols to this effect. Nevertheless, in many parts of the world, human activities such as animal production, still impact negatively on the environment and biodiversity. Some of the consequences of manmade pollution are transmission of diseases by water borne pathogens such as Enterococcus spp., eutrophication of natural water bodies, accumulation of toxic waste or recalcitrant chemicals in the soil, destabilization of ecological balance and negative effects on human health. The aim of this study was to carry out quality indices survey of Enterococcus spp. from the abattoir environment in Benin City, Edo State, Nigeria.

\section{MATERIALS AND METHODS Study Area}

Two abattoirs were used in this study and designated as station $\mathrm{A}$, located at Ewah road and Station B, located along Ikpoba hill road, Benin City, Nigeria. Both abattoirs use borehole as their source of water. However, abattoir station A connected its borehole to underground reservoir (locally called well) while abattoir station B connected its borehole to an overhead tank. The underground reservoir and overhead tank were then designated as the water source. The water used to wash the carcass of the already butchered meat was designated as water samples from the point of usage. The point of discharge was designated as the point where the used water flows into the drains.

\section{Sample Collection}

Samples were obtained from the water source, point of usage and point of discharge between February and July, 2017. Samples were obtained using $2 \mathrm{~L}$ sterile plastic containers and immediately placed on ice. Samples were thereafter conveyed to the laboratory for physicochemical and microbiological analysis within $2 \mathrm{~h}$ after collection.

\section{Physicochemical Analysis}

The $\mathrm{pH}$ of the water samples collected was determined in the laboratory using the Hanna $\mathrm{pH}$ meter, HI-1922 model. A conductivity meter (WTW Series Cond 730) was used to measure the conductivity of water samples. A $\mathrm{HACH}$ colorimeter was used for determining total suspended solids, total dissolved solids, colour and turbidity. The HACH colorimeter (Dr/890) was used in the analysis of phosphate, sulphate and nitrate. Chloride, dissolved oxygen and biochemical oxygen demand were assessed using the standard method (APHA-AWWW, 1985).

\section{Enumeration and Isolation of Bacterial Isolates}

An aliquot of $0.1 \mu$ l of the samples from the water source was inoculated into the Nutrient agar (Lab M, Lancashire, United Kingdom) and Bile Esculin Azide agar (Lab M, Lancashire, United Kingdom) for heterotrophic and enterococci enumeration respectively. Samples from water source, point of usage and point of discharge were serially diluted respectively prior to its inoculation onto the Nutrient agar and Bile Esculin Azide agar. Plates were thereafter incubated aerobically at $37^{\circ} \mathrm{C}$ for 18-24 h. After incubation, bacterial colonies were enumerated on the Nutrient agar and expressed as colony forming units per $\mathrm{ml}$ (cfu/ml). Black hallow colonies on Bile Esculin Azide agar were considered as presumptive enterococci colonies and were enumerated and expressed as $\mathrm{cfu} / \mathrm{ml}$. Thereafter, an average of 3 to 4 enterococci isolates was selected per positive plate and subcultured on fresh Bile Esculin Azide agar and incubated aerobically at $37^{\circ} \mathrm{C}$ for $18-24$ h. Isolates were then purified on Nutrient agar and stored on agar slants at $4{ }^{\circ} \mathrm{C}$ until ready for further analysis.

\section{Characterization and Identification of Bacterial Isolates}

Bacterial isolates were identified on the basis of cultural, morphological, biochemical tests such as Gram-stain, indole, oxidase, catalase, and Analytical Profile Index 20 NE (API 20NE) was used to confirm the identity of the Enterococcus species according to the manufacturer's 
instructions (BioMerieux, Marcy-l'Étoile, France).

\section{Antimicrobial Susceptibility Profile of the Enterococcus Species}

Antimicrobial susceptibility testing was carried out by the Kirby-Bauer disc diffusion method in accordance with the criteria of Clinical Laboratory Standards Institute (CLSI, 2017). A suspension of the test isolates was aseptically streaked on Mueller-Hilton agar plates, and the respective antibiotics discs were aseptically placed on the Mueller-Hilton agar plates. The disc

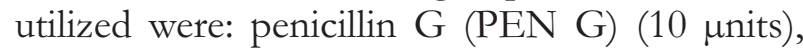
piperacillin (PTZ) $(100 \mu g)$, streptomycin (STR) $(10 \mu \mathrm{g})$, kanamycin $(\mathrm{KAN})(30 \mu \mathrm{g})$, tetracycline (TET) $(30 \mu g)$, imipenem (IMP) $(10 \mu g)$, meropenem (MEM) $(10 \mu g)$, ertapenem (ETP) (10 $\mu g$ ), cefuroxime (CRO) $(30 \mu g)$, cefotaxime (CTX) $(30 \mu g)$, erythromycin (ERY) $(15 \mu g)$, clindamycin (CLI) $(30 \mu g)$, ciprofloxacin (CIP) $(10 \mu g)$ and vancomycin (VAN) $(30 \mu \mathrm{g})$. The Agar plates were allowed to dry for $10 \mathrm{~min}$ and incubated at $37^{\circ} \mathrm{C}$ for $24 \mathrm{~h}$. The diameter of the inhibitory zone was measured using a transparent meter rule and interpreted as Resistant (R), Intermediate resistant (I), Sensitive (S) in accordance with the recommended standards established by the Clinical Laboratory Standards Institute (CLSI, 2017).

\section{Statistical Analysis}

All data in this study were analysed using the statistical package (SPSS) version 21.0 and Microsoft Excel 2013. Descriptive statistics were used to analyse the physicochemical and microbial data in mean and standard deviation. One-way Analysis of Variance (ANOVA) was used to analyse multiple variable while Duncan Multiple Range test was used to show significant difference between mean. Probability value less than 0.05 was considered statistically significant.

\section{RESULTS}

\section{Physicochemical Variables of Water from the Abattoir Environments}

The mean range of water physicochemical parameters (Table 1) in this study is as follows: $\mathrm{pH}$ (5.36 $\pm 0.85-7.35 \pm 0.28)$, colour (22.00 \pm 0.28 $7025.00 \pm 0.85$ pt.Co), EC $(256.00 \pm 0.14-$ $1338.33 \pm 0.07 \mu \mathrm{S} / \mathrm{cm})$, turbidity $(3.50 \pm 0.32-$ $428.50 \pm 0.51 \mathrm{NTU})$, TDS (138.98 $\pm 0.07-807.25$ $\pm 0.48 \mathrm{mg} / \mathrm{L})$, chloride $(27.06 \pm 0.06-149.26 \pm$ $0.05 \mathrm{mg} / \mathrm{L})$, phosphate $(0.39 \pm 0.31-21.28 \pm 0.01$ $\mathrm{mg} / \mathrm{L})$, sulphate $(2.83 \pm 0.26-225.83 \pm 0.22$ $\mathrm{mg} / \mathrm{L})$, nitrate $(3.87 \pm 0.43-208.54 \pm 0.32 \mathrm{mg} / \mathrm{L})$, dissolved oxygen (DO) $(0.83 \pm 1.94-6.13 \pm 0.13$ $\mathrm{mg} / \mathrm{L})$, BOD $(3.00 \pm 0.40-272.45 \pm 0.14 \mathrm{mg} / \mathrm{L})$, and $\operatorname{COD}(35.66 \pm 0.13-797.10 \pm 0.35 \mathrm{mg} / \mathrm{L})$. 
至 年

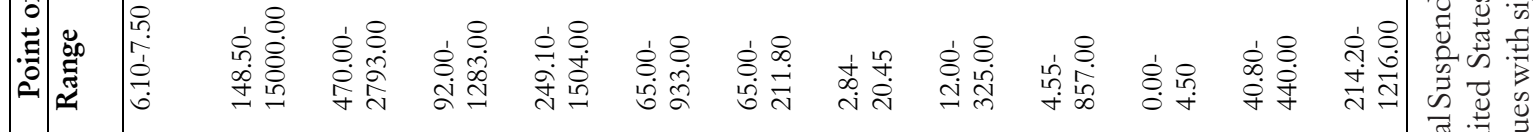

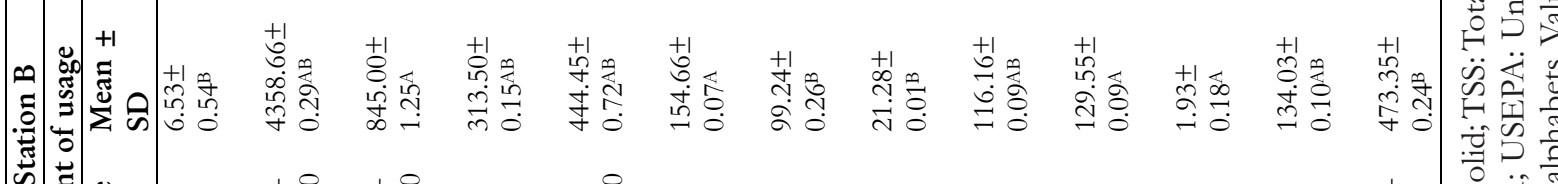

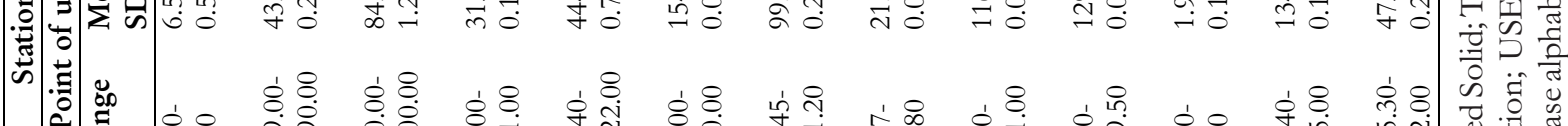

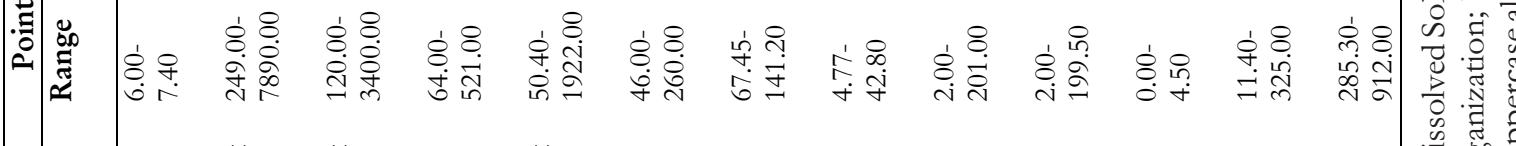

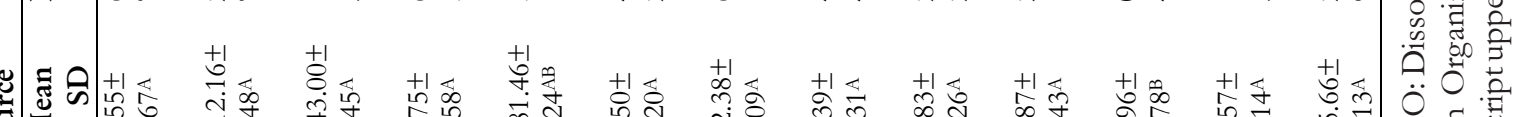

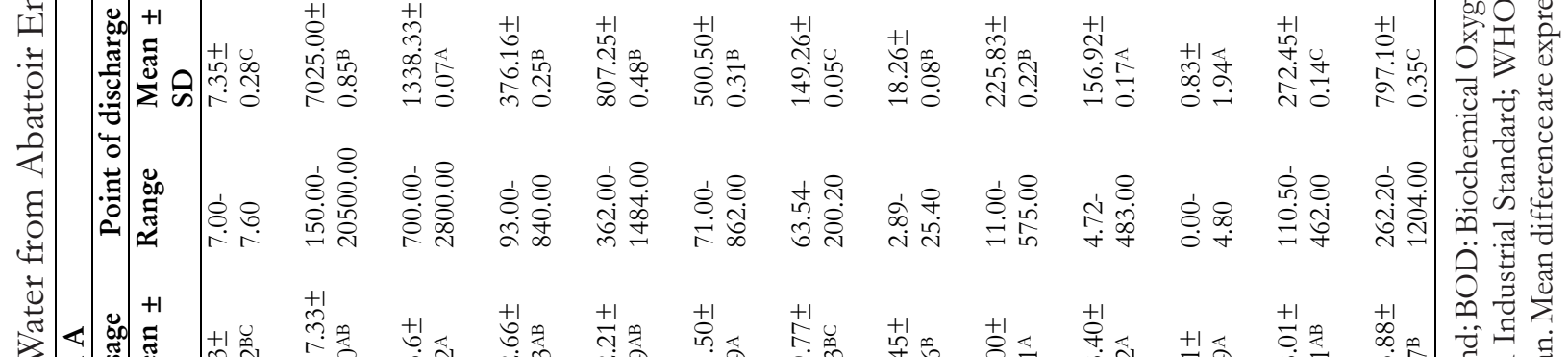

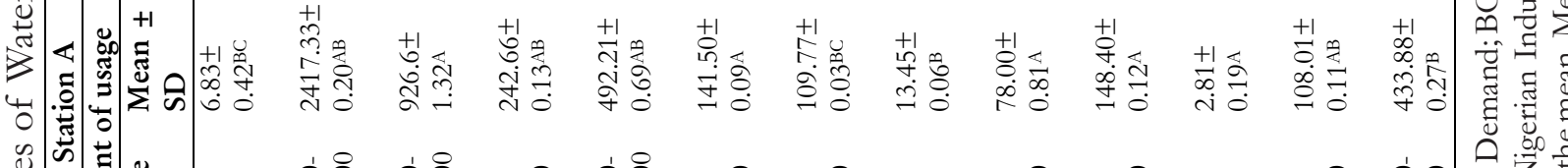

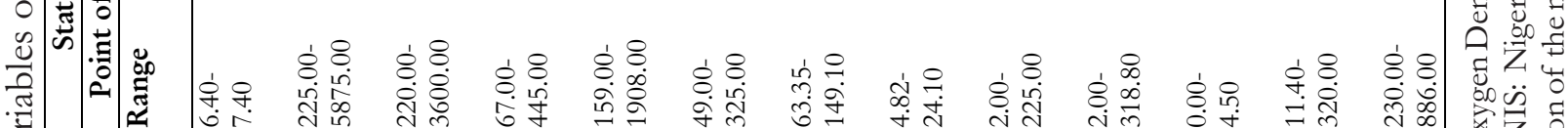

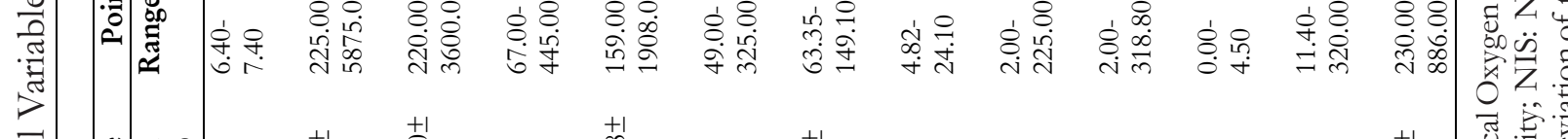

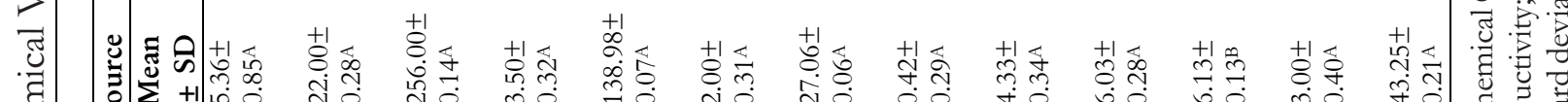
它 | 
Microbial Counts of Water Sampled from the Abattoir Environments

The mean range of microbial population cell density in this study (Table 2) was: mesophilic bacteria $\left[(6.51 \pm 0.61) \times 10^{7}-(1.92 \pm 0.11) \times 10^{8}\right.$ $\mathrm{cfu} / \mathrm{ml})]$ and Enterococcus species $[(6.66 \pm 1.63)$ $\left.\left.\times 10^{1}-(1.16 \pm 0.05) \times 10^{4} \mathrm{cfu} / \mathrm{ml}\right)\right]$.

\section{Correlation of the Water Physicochemical} Variables and Bacterial Cell Counts

In station A (Table 3), $\mathrm{pH}$ significantly correlates with colour, turbidity, total suspended solids (TSS), chloride, phosphate, sulphate, nitrate, DO, BOD, COD, and Enterococcus species density. In station B (Table 4), TSS significantly correlates with chloride, DO, BOD, COD, and Enterococcus species density. Chloride significantly correlates with DO, BOD, COD, and Enterococcus species density.

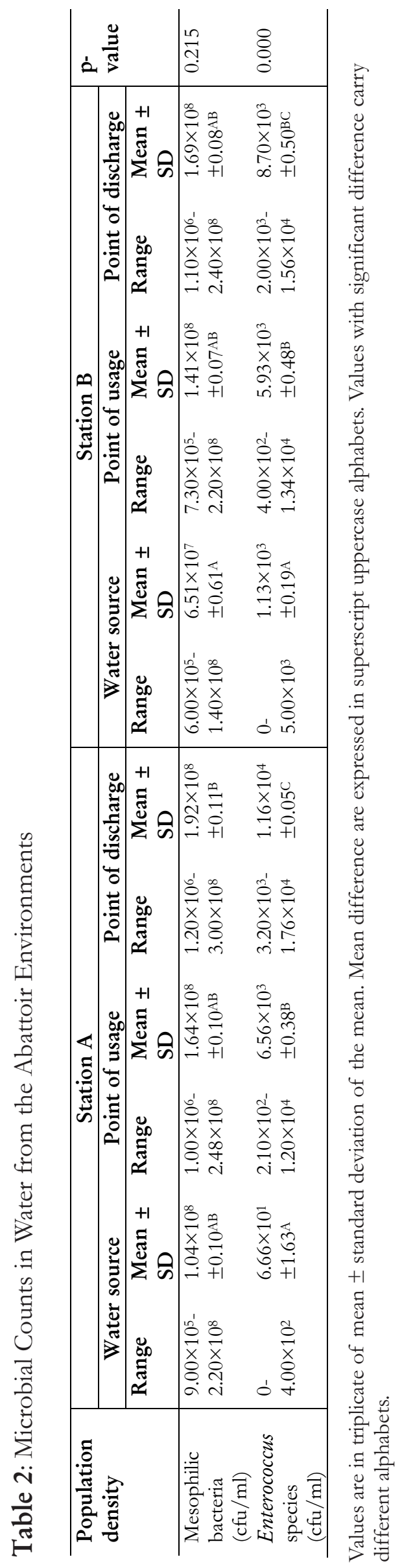




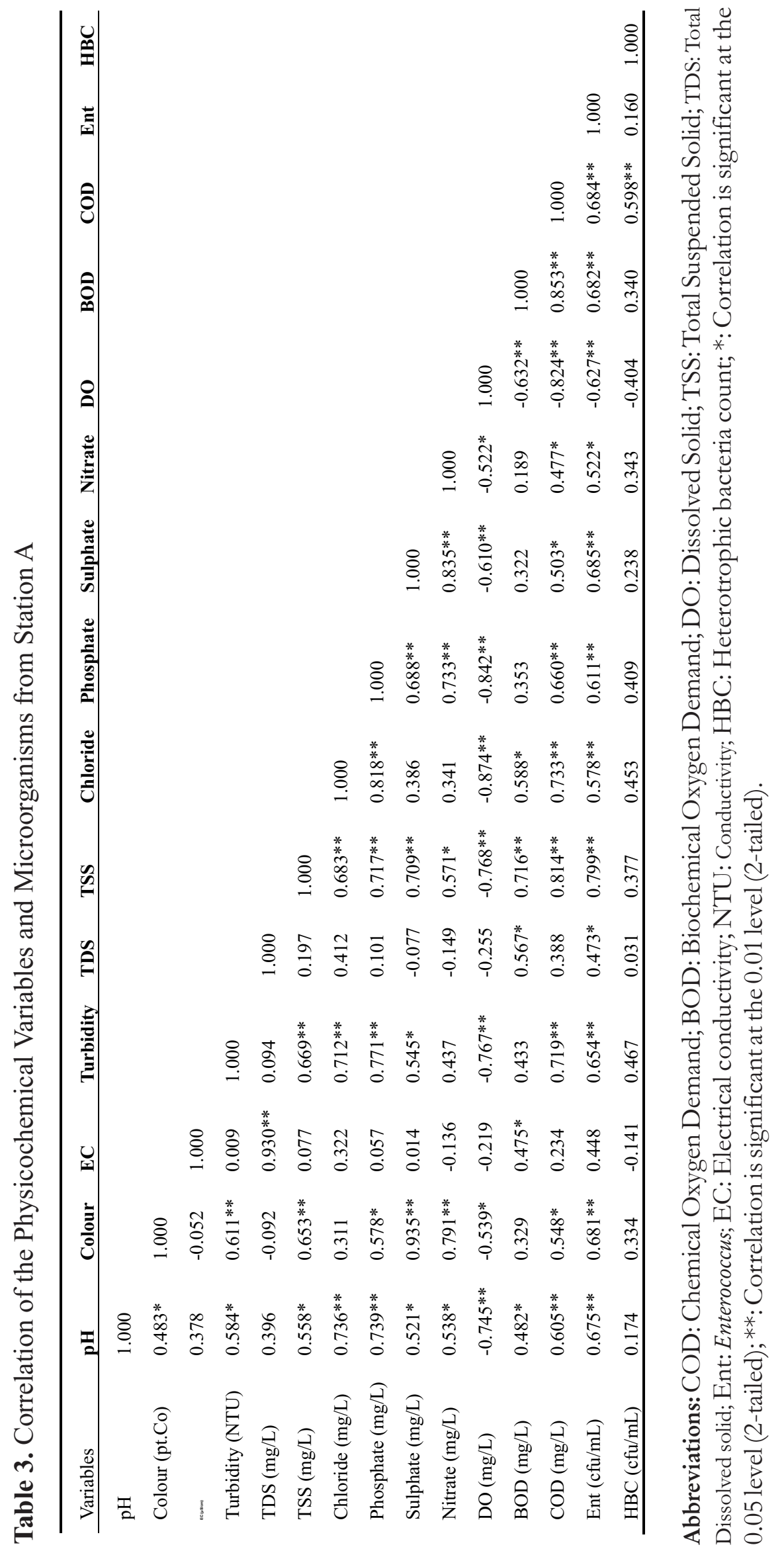




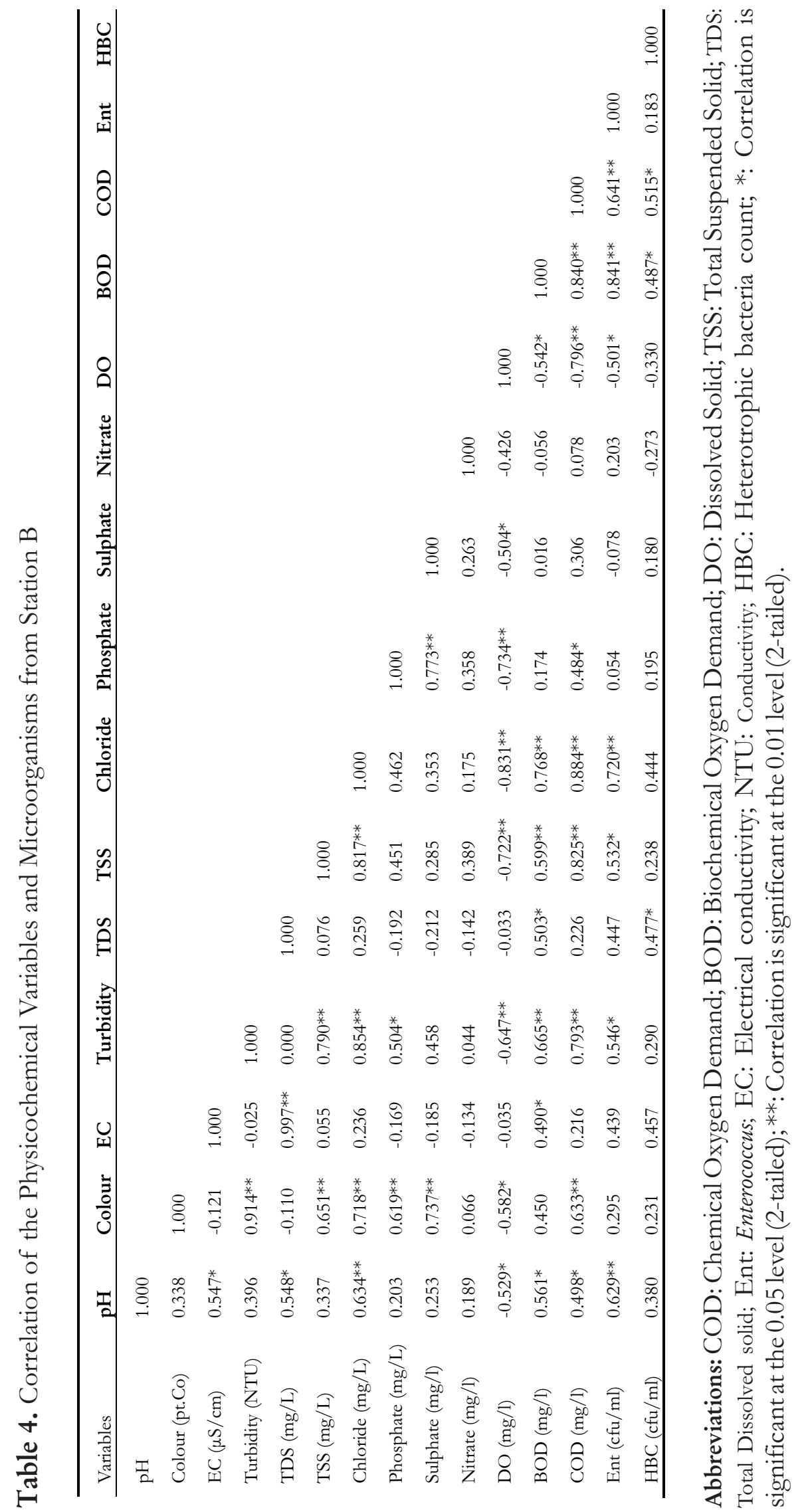


088 Igbinosa and Raje: Characterization of Enterococcus Species Isolated from Abattoir Environment

Percentage Frequency of Occurrence of the Enterococcus species in Sampled Water The percentage frequencies of occurrence of Enterococcus species (Figure 1) in this study were: E. faecalis 19(29.7\%), E. faecium 23(35.9\%), E. durans $9(14.1 \%)$, E. casseliflavus $8(12.5 \%)$, and $E$. birae $5(7.8 \%)$.
Distribution of Enterococcus species in Water from the Abattoir Environment The distributions of confirmed Enterococcus species from abattoir environment via API 20NE were: 1 to 9 isolates from point of usage; 2 to 15 isolates from point of discharge while no isolate was detected at water source (Figure 2).

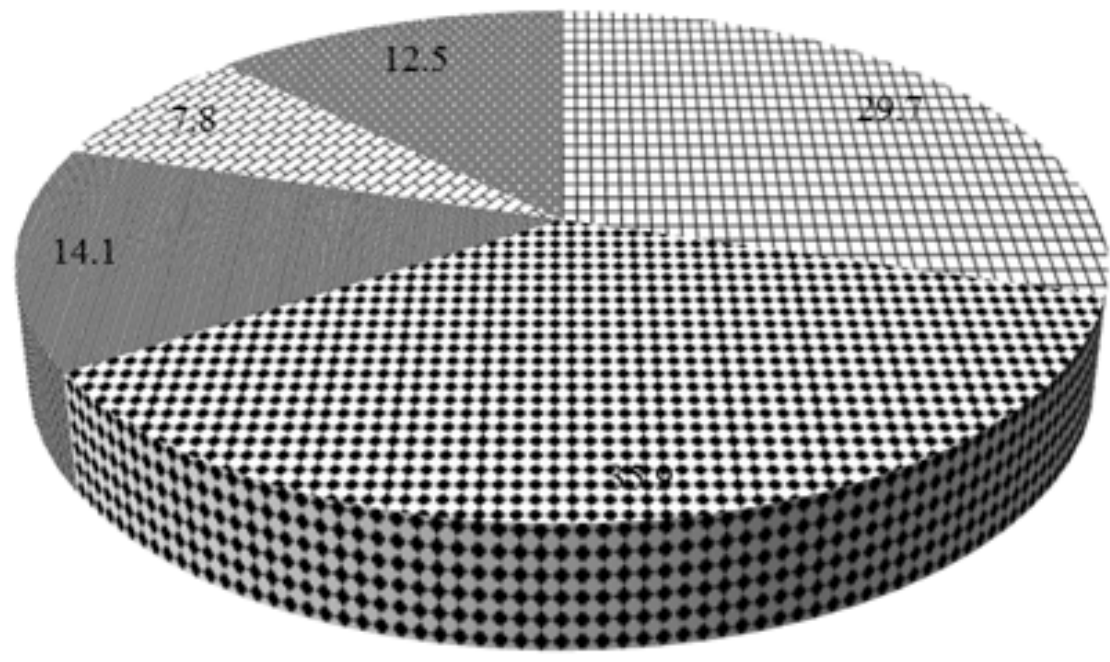

\begin{tabular}{|c|c|}
\hline$\Pi$ Enterococcus faecalis $n=19$ & $\bullet$ Enterococcus faecium $n=23$ \\
\hline Enterococcus durans $n=9$ & $\therefore$ Enterococcus hirae $n=5$ \\
\hline
\end{tabular}

Figure 1. Percentage frequency of occurrence of the Enterococcus species

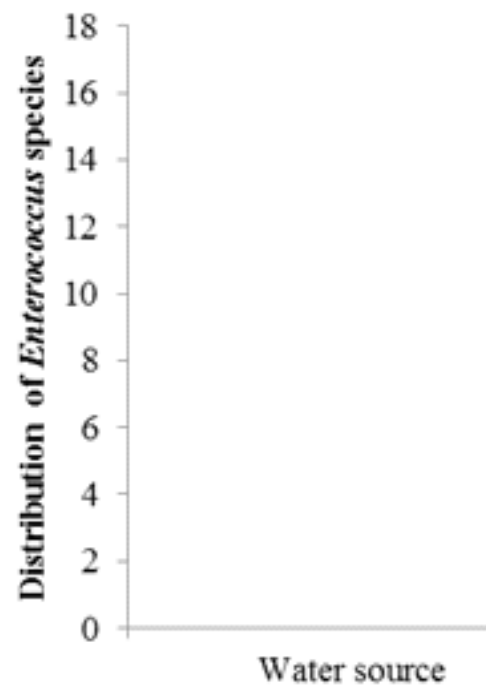

: Enterococcus faecalis

Enterocaccus hirae

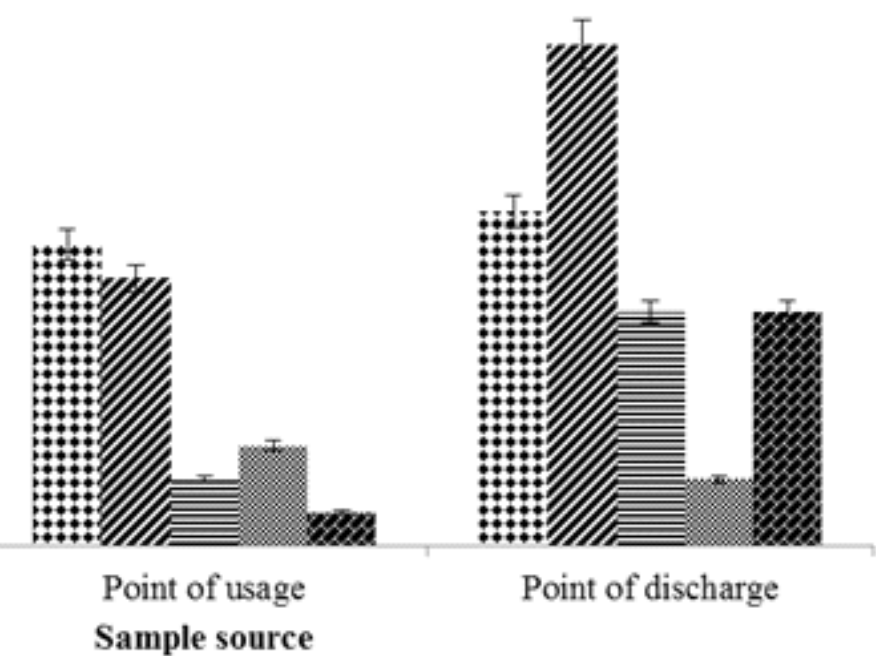

$\boldsymbol{\sim}$ Enterococcus faecium $\quad \equiv$ Enterococcus durans

- Enterococcus casseliflavus

Figure 2: Distribution of Enterococcus species from the Abattoir Environment 


\section{Antimicrobial Susceptibility of Enterococcus species from Abattoir Environment}

Resistance profile of Enterococcus species (Table 5) revealed that $64(100 \%)$ were resistant to ertapenem, cefuroxime and cefotaxime. In addition, $54(84.4 \%)$ were resistant to meropenem, $51(79.7 \%)$ were resistant to penicillin, 34 (53.1) were resistant to tetracycline, $27(42.2 \%)$ were resistant to piperacillin, 24 $(37.5 \%)$ were resistant to clindamycin, and 23 $(35.9 \%)$ were resistant to vancomycin.

\section{Extensively Drug Resistant (XDR), Multidrug Resistant (MDR) and Multiple Antibiotics Resistant (MAR) Index of the Enterococcus species}

A total of $4(21.1 \%)$ E. faecalis were resistant to 11 antibiotics $\left(\mathrm{PEN}^{\mathrm{R}}, \mathrm{PTZ}^{\mathrm{R}}, \mathrm{ETP}^{\mathrm{R}}, \mathrm{MEM}^{\mathrm{R}}, \mathrm{TET}^{\mathrm{R}}\right.$, $\mathrm{CLI}^{\mathrm{R}}, \mathrm{ERY}^{\mathrm{R}}, \mathrm{CIP}^{\mathrm{R}}, \mathrm{CRO}^{\mathrm{R}}, \mathrm{CTX}^{\mathrm{R}}$, and $\mathrm{VAN}^{\mathrm{R}}$ ) which belong to 8 groups of antimicrobial with an MAR index of 0.79 . A total of $7(30.4 \%)$ of $E$. faecium were resistant to 10 antibiotics $\left(\mathrm{PEN}^{\mathrm{R}}\right.$, $\mathrm{PTZ}^{\mathrm{R}}, \mathrm{ETP}^{\mathrm{R}}, \mathrm{MEM}^{\mathrm{R}}, \mathrm{TET}^{\mathrm{R}}, \mathrm{CLI}^{\mathrm{R}}, \mathrm{CIP}^{\mathrm{R}}, \mathrm{CRO}^{\mathrm{R}}$, CTX $^{\mathrm{R}}$, and $\mathrm{VAN}^{\mathrm{R}}$ ) which belong to 7 groups of antimicrobial with an MAR index of 0.71. A total of $2(22.2 \%)$ of $E$. durans were resistant to 12 antibiotics $\left(\mathrm{PEN}^{\mathrm{R}}, \mathrm{PTZ}^{\mathrm{R}}, \mathrm{ETP}^{\mathrm{R}}, \mathrm{MEM}^{\mathrm{R}}, \mathrm{KAN}^{\mathrm{R}}\right.$, $\mathrm{TET}^{\mathrm{R}}, \mathrm{CLI}^{\mathrm{R}}, \mathrm{ERY}^{\mathrm{R}}, \mathrm{CIP}^{\mathrm{R}}, \mathrm{CRO}^{\mathrm{R}}, \mathrm{CTX}^{\mathrm{R}}$, and VAN $^{\mathrm{R}}$ ) which belong to 9 groups of antimicrobial with an MAR index of 0.86 . A total of $2(40 \%)$ of E. hirae were resistant to 7 antibiotics $\left(\mathrm{PEN}^{\mathrm{R}}\right.$, ETP $^{\mathrm{R}}, \mathrm{MEM}^{\mathrm{R}}, \mathrm{TET}^{\mathrm{R}}, \mathrm{CRO}^{\mathrm{R}}, \mathrm{CTX}^{\mathrm{R}}$, and $\mathrm{VAN}^{\mathrm{R}}$ ) which belong to 5 groups of antimicrobial with an MAR index of 0.50 . A total of $3(37.5 \%)$ of $E$. casseliflavus were resistant to 7 antibiotics $\left(\mathrm{PEN}^{\mathrm{R}}\right.$, $\mathrm{ETP}^{\mathrm{R}}, \mathrm{MEM}^{\mathrm{R}}, \mathrm{TET}^{\mathrm{R}}, \mathrm{CLI}^{\mathrm{R}}, \mathrm{CRO}^{\mathrm{R}}$, and $\mathrm{CTX}^{\mathrm{R}}$ ) which belong to 5 groups of antimicrobial with an MAR index of 0.50 . In total, $23(35.9 \%)$ of Enterococcus species were resistant to 9 antibiotics $\left(\mathrm{PEN}^{\mathrm{R}}, \mathrm{PTZ}^{\mathrm{R}}, \mathrm{ETP}^{\mathrm{R}}, \mathrm{MEM}^{\mathrm{R}}, \mathrm{TET}^{\mathrm{R}}\right.$, $\mathrm{CLI}^{\mathrm{R}}, \mathrm{CRO}^{\mathrm{R}}, \mathrm{CTX}^{\mathrm{R}}$, and $\mathrm{VAN}^{\mathrm{R}}$ ) which belong to 6 groups of antimicrobial with an MAR index of 0.64 (Table 6).

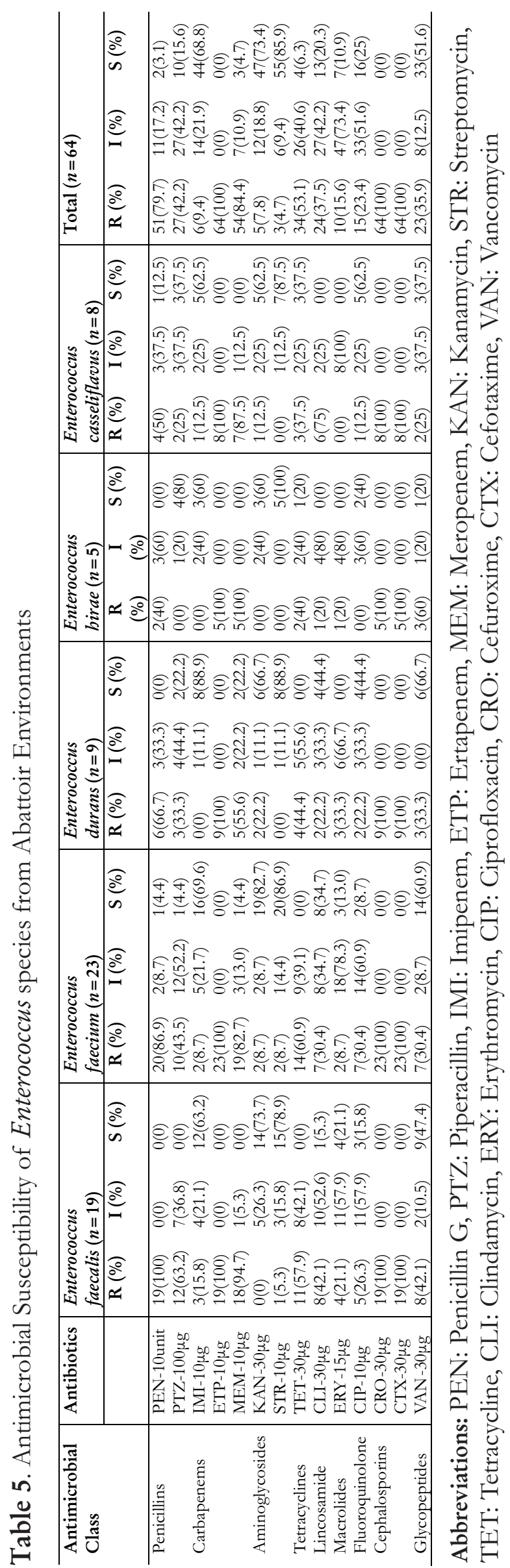


Igbinosa and Raje: Characterization of Enterococcus Species Isolated from Abattoir Environment

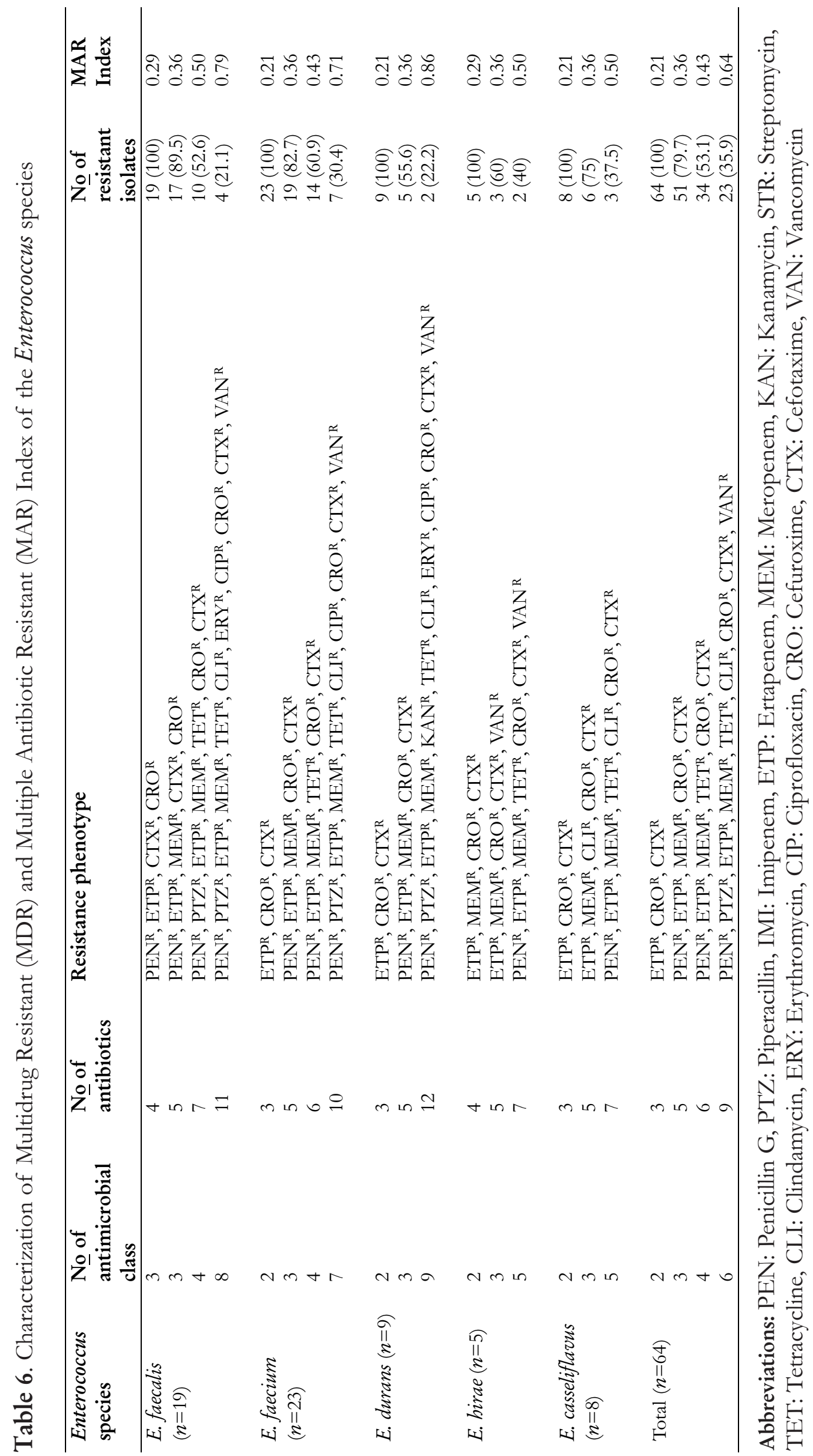




\section{DISCUSSION}

The interest to increase the production of meat to meet the demand for protein requirements of the increasing population is usually linked with some pollution menace in Nigeria. The present study has revealed the physicochemical matrix and enterococci diversity of abattoir source water and effluent in Benin City, Nigeria. The meat industry generates enormous amount of untreated wastewater which are discharged into surrounding water bodies (Rabah et al., 2010).

A significant effect of untreated wastewater discharge into water bodies makes the oxygen in that environment less accessible as an electron acceptor, thereby stimulating denitrifying microorganisms to decrease the available nitrate to gasiform nitrogen which finds its way into the atmosphere culminating in negative side effects. On a similar note, the physicochemical characteristics such as the $\mathrm{pH}$ of the receiving water/soil may become different, as a result of the untreated discharge of abattoir effluent resulting in the inhibition of certain soil microbes and proliferation of other microbes, hence adverse effect on soil microbial community (Rabah et al., 2010).

Following the discharge of untreated wastewater into the environment, certain elements such as iron, phosphorus, lead, zinc and calcium which were previously present in minute quantities or absent are introduced into the environ which results to the magnification of these chemicals thereby altering the physicochemical nature of that environment. Some of these alterations may alter the dynamics and communities of the receiving soil/water environment. Some of the wastewater from abattoirs in Benin metropolis drains into the surrounding soil and the Ikpoba River through the abattoir drainages. This could result in the degradation of soil fertility as a result of the accumulation of certain nutrients and heavy metals that may result to low productivity in the surrounding farmlands, coupled with destructions of aquatic lives. Since the water from both the River are used for irrigation farming along the River banks, as well as for other domestic and commercial usage, the possibility of zoonotic diseases amongst the end users cannot be excluded.
The high counts of both heterotrophic bacteria and Enterococcus species obtained indicated that the water samples from the point of usage and discharged effluent had a high population density compared to the source water samples. In addition, it revealed a significant difference $(p<$ $0.05)$ between the population densities in the samples from the point of usage and discharged effluent compared to the source water samples. This can be attributed to the fact that the effluents may contain lots of growth factors that could easily be metabolized and/or utilized by the organisms which are absent or in low quantity in the source water.

Also, it may be connected to the disruption of the ecological balance resulting from contamination due to the release of the abattoir wastewater into the environment. The abundance and occurrence of high population of heterotrophic bacteria observed in the point of usage and discharged effluent may be expected as these organisms are indigenous and known to persist in such environment. However, the presence of Enterococcus species in the point of usage and discharged effluent may be attributable to the remains of animal excreta in the wastewater during or after slaughter.

The temperature and $\mathrm{pH}$ values observed from this study revealed no significant fluctuation at the point of usage and discharged effluent but there was significant difference when compared with abattoir source water. These two factors are crucial in determining both the quantitative and qualitative diversity of microorganisms in the abattoir source water and effluent. Similarly, significant differences $(p>0.05)$ were obtained for nitrate, sulphate, colour, electrical conductivity, total dissolved solids, total suspended solids, chloride, biochemical oxygen demand and chemical oxygen demand in the abattoir discharged effluent and abattoir source water.

Concentration of dissolved oxygen (DO) in the source waters and effluents depends on the chemical, biochemical and physical activities in the water body. $\mathrm{DO}$ values recorded in this study were lower than the World Health Organization (WHO) and Nigerian Industrial Standard (NIS) 
water quality standards (WHO, 2004; NIS, 2007). This could be connected to increased levels of organic loads, total solids and nutrient content of effluents in the slaughterhouse. The DO is important for the continued existence of aquatic life. Dissolved oxygen has the capability to alter the microbial diversity in an aquatic environment (Igbinosa and Uwidia, 2018).

An infinitesimal / or no DO was detected in the point of usage and discharged effluent and this may be as a result of elevated levels of total suspended solids and nutrient content of the abattoir effluents. A previous finding of low dissolved oxygen at discharged point has been documented (Igbinosa and Uwidia, 2018). The absolute depletion of DO in the discharged effluent could also be attributed to the huge amount of organic matter which requires elevated levels of molecular oxygen for chemical oxidation, breakdown of nutrients or mineralization thus diminishing existing oxygen vital for respiration. Similar studies of DO have been reported from Ethiope River receiving effluent of saw mill (Arimoro et al., 2007) and Minna River receiving effluent from slaughterhouses (Chukwu et al., 2008).

The dissolved oxygen value obtained from the source water could be attributed to the low level of turbidity with elevated transparency which allows for appropriate penetration by sunlight resulting in an upsurge in photosynthetic activity within such environment. The decomposition of organic abattoir waste by microorganisms exerts significant biochemical oxygen demand (BOD) and consequently generates anaerobic conditions leading to the introduction of pathogens and bacteria into the environment and also resulting in eutrophication thus stimulating nutrients like phosphate and nitrate. High BOD values at the point of discharge could be connected to the reduced DO level, as decreased DO results in an upsurge in BOD resulting in a strong indication of pollution (Chukwu et al., 2007). DO describe the level of pollution by organic material, the breakdown of organic matter coupled with the self-purification capability of the wastewater (Akanetal., 2010).

The chemical oxygen demand (COD) at the effluent discharge point was higher than the recommended values for good water quality. The higher COD values when compared to $\mathrm{BOD}$ values obtained in this study could be as a result of organic substances that were not metabolizable by aerobic bacteria. Likewise, this may be as a result of the fact that most of the organic matters are ultimately decomposed chemically or anaerobically. Hence BOD measures the available oxygen for biological activities while COD elucidates all the oxidizable organics.

In addition, elevated COD value of the discharged effluent could be attributed to high organic load resulting from total dissolved solid and total suspended solid from these slaughterhouses. This explains the correlation that exists between TSS, COD and TDS (Osibanjo and Adie, 2007). It is important to note that COD values from the source water were low compared to COD from the effluent water. This could be ascribed to high chloride content, dilution of minute organics present and very low electrical conductivity as well as low/no turbidity in source water. COD values obtained from this study was low when compared to several other findings. Osibanjo and Adie (2007) reported a COD value within the range of 947-2566 mg/L from Bodija abattoir. This could be as a result of the fact that the effluents were obtained from slaughterhouses compared to those of Osibanjo and Adie (2007) that was obtained from flowing river receiving effluent from abattoir environment (dilution factor).

Electrical Conductivity (EC) is a measure of conducting ionic components in a solution. It was recorded in significant levels in the effluent water. These values observed could be connected to the elevated levels of conducting elements such as phosphate and chloride. Nitrate values from the point of usage and discharged effluent were high and exceeded the permissible limits. Possible routes of nitrogenous wastes include moderately absorbed food from the gut of butchered animals. Sources of chloride and phosphate can be attributed to the detergents applied in the abattoir by the abattoir workers to wash the roasted slaughtered animals (Osibanjo and Adie, 2007).

Vancomycin resistant Enterococcus species (VREs) were reported among 25\% of the 
Enterococcus spp. isolates that were obtained from environments around Intensive Care Units (ICU) by Tajeddin et al. (2016). In addition, nearly $50 \%$ of the enterococci isolates from that environment were resistant to this antibiotic (Tajeddin et al., 2016). Enterococci population density from the effluent in this study was lower than those recovered from wastewater treatment plants by Sadowy and Luczkiewicz (2014). Resistance to erythromycin was detected by Sadowy and Luczkiewicz (2014) as the highest among $E$. faecalis and $E$. faecium. This was not the case in this study.

Resistance to ciprofloxacin among E. faecium differ between $30.8 \%$ and $44.8 \%$ (Sadowy and Luczkiewicz, 2014). Eight different Enterococcus species (Enterococcus faecium, Enterococcus faecalis, Enterococcus mundtii, Enterococcus casseliflavus, Enterococcus gallinarum, Enterococcus dispar, Enterococcus avium and Enterococcous hirae) were isolated from hospital environment in Abuja Nigeria by Ndubuisi et al. (2017) with $E$. faecalis as the most prominent with $57.8 \%$ followed by $E$. faecium with $23.5 \%$. This contradicts the findings from this study where $E$. faecium predominates over $E$. faecalis and can be attributed to difference in study locations and sample sources. Azza et al. (2013), recounted more detection of $E$. faecium in their findings. Findings from this study are also similar to the report of Cetinkaya et al. (2000) where E. casseliflavus, E. avium, E. durans and $E$. gallinarum were detected less frequently.

More than $50 \%$ of the enterococci isolates were resistant to rifampin, erythromycin and doxycycline by Ndubuisi et al. (2017). Antibiotic resistance could be associated to the abuse of antibiotics due to over-the-counter medication and accessibility to patients devoid of doctor's prescription due to upsurge of pharmacies and patent medicine stores. In addition, consumption of animal products treated with these antibiotics as growth promoters and prophylactic agents could have added to the resistance (Beshiru et al., 2017). Resistance profile from this study is comparable to the findings of Schwaiger et al. (2010) where Enterococcus spp. isolated from animal food revealed elevated resistance to erythromycin, rifampicin, doxycycline and fosfomycin.

Appreciable susceptibility to glycopeptides and aminoglycosides in this research were comparable to those of Ndubuisi et al. (2017). This gives assurance for synergistic treatment regimen of vancomycin resistant enterococcal infections such as urinary tract infections (UTI), endocarditis and bacteraemia. Ndubuisi et al. (2017) also reported that $33.3 \%$ of the enterococcal isolates were resistant to vancomycin which is similar to the findings of this study. Vancomycin resistance, high-level-clarithromycin, ampicillin, erythromycin, gentamicin and kanamycinresistant enterococci were reported from animal feed environment by Ali et al. (2013). Their findings revealed that antibiotic resistance differ with isolation source.

The acquisition of resistant determinants and exposure to different elements of antibiotics could have resulted in upsurge and emergence of intermediate or low level of enterococcal resistance to vancomycin in this study. Enterococci have been reported to acquire antibiotic resistance via conjugative transposition, plasmids or through mutations which resulted in the rapid dissemination of multidrug resistant enterococcal infections (Beshiru et al., 2017). In Nigeria, vancomycin resistant enterococci may soon become a significant threat since $35.9 \%$ of the 64 isolates in this study exhibited resistance to vancomycin. Adequate processes intended at curbing its dissemination needs to be employed. Water and environmental samples often harbour enterococci. Large quantities of animal and human waste are discharged into the environment through non-sewage or sewage systems. For the past decades, enterococci have been used as indicators of fecal pollution of food and water for human consumption. Effective wastewater treatment management is not practiced in the study areas. The water cycle has been regarded as a route for the transmission of antibiotic resistance (Tansuphasiri et al., 2006), due to direct release of poorly treated sewage into nearby rivers.

Dada et al. (2013) have recovered multidrug 
resistant (MDR) enterococci from coastal and storm waters that were channelled to recreational beaches within Malaysia. Findings suggest that these leisure sites may contribute to the spread of MDR enterococci and virulence elements therein (Dada et al., 2013). In another study that was carried out in Thailand, a significant prevalence of MDR enterococci (10.3\%) were vancomycinresistant Enterococcus (VRE) isolates, in water samples including agricultural wells of food animal farms, canals and rivers (Tansuphasiri et al., 2006). This again could suggest a significant route for the dissemination of MDR enterococci and resistance elements into the food chain and the environment that could significantly pose a public health threat.

\section{CONCLUSION}

The present study has described the physicochemical properties of water and antibiotic resistance of Enterococcus species recovered from two major abattoir environments within Benin City, Nigeria. The presence of high multiple antibiotic resistant indexes in Enterococcus species are significant to public health as these could be transmitted between animals and humans, and the environment via horizontal gene transfer. Findings from this study could be used as a baseline study to investigate outbreaks of pathogenic and multidrug resistant enterococci infections in abattoir environments. This information is helpful in establishing effective monitoring and infection control measures in slaughterhouses in Nigeria.

\section{REFERENCES}

Akan, J.C., Abdulrahman, F.I. and Yusuf, E. 2010. Physical and chemical parameters in abattoir wastewater sample, Maiduguri metropolis, Nigeria. Pacific Journal of Science and Technology, 11(1): 640-648.

Ali, S.A., Hasan, K.A., Bin, H. and Abbasi A. 2013. Environmental enterococci: Prevalence of virulence, antibiotic resistance and species distribution in poultry and its related environment in Karachi, Pakistan. Letters in Applied Microbiology, 58: 423432.

APHA and AWWA (1985). Health Association, Washigton, DC. Standard Methods for
Examination of Water and Wastewater. 16thAmerican Public

Arimoro, F.O., Chukwudi, M.A. and Ogheneghalome, O. 2007. Effect of industrial waste water on the physical and chemical characteristics of a tropical coastal river. Research in Environmental Science, 2: 209-220.

Azza, L., Ahmed, M., Nahed, A., Wafaa, Z. and Eman, E. 2013. Molecular and phenotypic characterization of hospital-associated and community associated isolates of Enterococcus spp. Menoufia Medical Journal, 26: 108-113.

Beshiru, A., Igbinosa, I.H., Omeje, F.I., Ogofure, A.G., Eyong, M.M. and Igbinosa, E.O. 2017. Multi-antibiotic resistant and putative virulence gene signatures in Enterococcus species isolated from pig farms environment. Microbial Pathogenesis, 104: 90-96.

Castillo-Rojas, G., Mazari-Hir I art, M., de-Leon, P.S., Amieva-Fernandez, R.I. and AgisJuarez, R.A. 2013. Comparison of Enterococcus faecium and Enterococcus faecalis strains isolated from water and clinical samples: Antimicrobial susceptibility and genetic relationships. PLoSONE, 8(4): 59481-59491.

Cetinkaya, Y., Falk, P. and Mayhall, C. 2000. Vancomycin resistant enterococci. Clinical Microbiology Reviews, 13(4): 686-707.

Chukwu, O., Ajisegiri, E.S.A., Onifade, K.R. and Jimoh, O.D. 2007. Environmental impact auditing of food processing industry in Nigeria: The case of climate and air quality. $A U$ University Journal of Technology, 11:77-85.

Chukwu, O., Mustapha, H.I. and Gafar, H.B.A. 2008. The effect of Minna abattoir waste water on surface water quality. Environmental Research Journal, 3: 334338.

Clinical and Laboratory Standards Institute (CLSI), 2017. Performance Standards for Antimicrobial Susceptibility Testing M02A12, M07-A10, and M11-A8. 27th Edition; 282pp.

Dada, A.C., Ahmad, A., Usup, G. and Heng, L.Y. 
2013. Speciation and antimicrobial resistant of enterococci isolated from recreational beaches in Malaysia. Environmental Monitoring and Assessessment, 185:1583-1599.

Igbinosa I.H and Uwidia I.E. 2018. Effect of abattoir effluents on the physicochemical properties of a receiving watershed in an urban community. Ife Journal of Science. 20(2): 207-214.

Iweriebor, B.C., Gaqavu, S., Obi, L.C., Nwodo, U.U. and Okoh A.I. 2015. Antibiotic susceptibilities of Enterococcus species isolated from hospital and domestic wastewater effluents in Alice, Eastern Cape Province of South Africa. International Journal of Environmental Research and Public Health, 12: 42314246.

Martins, E., Novais, N., Freitas, A.R., Dias, A.R., Ribeiro, T.G., Antunes, P. and Peixe, L. 2015. Filling the map for antimicrobial resistance in Sub-Saharan Africa: Ampicillin-resistant Enterococcus from non-clinical sources in Angola. Journal of Antimicrobial Chemotherapy, 70:42-51.

Ndubuisi, J.C., Olonitola, O.S., Olayinka, A.T., Jatau, E.D. and Iregbu, K.C 2017. Prevalence and antibiotics susceptibility profile of Enterococcus spp. isolated from some hospitals in Abuja, Nigeria. African Journal of Clinical and Experimental Microbiology, 18(3):154-158.

Nigerian Industrial Standard (NIS) 2007. Nigerian standard for drinking water quality, NIS 554:2007, ICS 13.060.20, Approved by the Standard Organisation of Nigeria (SON) Governing Council, pp: 14-18.

Osibanjo, O. and Adie, G.U. 2007. Impact of effluent from Bodija abattoir on the physico-chemical parameters of Oshunkaye stream in Ibadan City, Nigeria. African Journal of Biotechnology, 6: 18061-18081.

Rabah, A.B., Oyeleke, S.B., Manga, S.B., Hassan, L.G., and Ijah, U.J.J. 2010. Microbiological and physico-chemical assessment of soil contaminated with abattoir effluents in Sokoto metropolis, Nigeria. Scientific World Journal, 5(3): 1-4

Sadowy, E. and Luczkiewicz, A. 2014. Drugresistant and hospital-associated Enterococcus faecium from wastewater, riverine estuary and anthropogenically impacted marine catchment basin. BMC Microbiology, 14: 66-75.

Schwaiger, K., Schmied, E. and Bauer, J. 2010. Comparative analysis on antibiotic resistance characteristics of Listeria spp. and Enterococcus spp. isolated from laying hens and eggs in conventional and organic keeping systems in Bavaria, Germany. Zoonoses Public Health, 57(3): 171-180.

Sedlacek, I., Holochova, P., Maslanova, I., Kosina, M., Sproer, C., Bryndova, H., Vandamme, P., Rudolf, I., Hubalek, Z. and Svec, P. 2013. Enterococcus ureilyticus sp. nov. and Enterococcus rotai sp. nov., two urease-producing enterococci from the environment. International Journal of Systematic and Evolutionary Microbiology, 63: 502-510.

Tajeddin, E., Rashidan, M., Razaghi, M., Javadi, S.S.S., Sherafat, S.J., Alebouyeh, M., Sarbazi, M.R., Mansouri, N. and Zali, M.R. 2016. The role of the intensive care unit environment and health-care workers in the transmission of bacteria associated with hospital acquired infections. Journal of Infection and Public Health, 9: 13-23.

Tansuphasiri, U., Khaminthakul, D. and Pandii, W. 2006. Antibiotic resistance of enterococci isolated from frozen foods and environmental water. Southeast Asian Journal of Tropical Medicine and Public Health, 37: 162-170.

United State Environmental Protection Agency (USEPA), 2004. EPA groundwater and drinking water current standards. EPA office of water, Washington DC, USA.

World Health Organization (WHO) (2004). Guidelines for drinking water quality. World Health Organization, Geneva, Switzerland. 